\title{
PREREQUISITES FOR THE MODELLING OF EMPTY CONTAINER SUPPLY CHAINS
} pages: $28-36$

\author{
Katarzyna Anna Kuźmicz, ERWIn Pesch
}

\begin{abstract}
A B S TR A C T
Containerisation of freight transport significantly facilitates the flow of traded goods between remote destinations. The most important container transport routes link Asia with North America and Europe. The seasonality and imbalance of trade are the main factors giving rise to problems related to empty container repositioning. The aim of this paper is to develop a concept of empty container supply chains and formulate prerequisites for its modelling in the search for the optimal solution with the help of linear programming and mixed integer programming methods. This paper indicates causes of the empty container relocation problem based on the literature analysis with a special focus on the Eurasian transportation route. Also, it provides a concept of empty container supply chain, prerequisites for its modelling and examples of container supply chains modelling presented in the literature. The main results of the paper include conceptualisation of an empty container supply chain and suggested modelling prerequisites. The paper contributes to research in the field of supply chain management and optimisation of transportation.
\end{abstract}

KE Y W OR D S

container transportation, supply chains, modelling, optimisation methods

DOI: 10.1515/emj-2017-0023
Corresponding author:

Katarzyna Anna Kuźmicz

Bialystok University of Technology, Faculty of Management, International China and Central-Eastern Europe Institute of Logistics and Service Science, Poland e-mail:k.kuzmicz@pb.edu.pl

Erwin Pesch

University of Siegen, Faculty III: School of Economic Disciplines, Management Information Science, Centre for Advanced Studies in Management, HHL Leipzig Graduate School of Management, Germany e-mail: erwin.pesch@uni.siegen.de

\section{INTRODUCTION}

Containerisation was a breakthrough solution in cargo transportation and had an undisputable influence on global supply chains. However, it is not that freight is moving faster along the respective modes servicing supply chains, but that the cargo handling efficiency at container terminals, where usually the transport mode is changed, has signifi- cantly increased the velocity of transhipments and, consequently, of supply chains (Notteboom \& Rodrigue, 2008). Containerisation enabled the expansion to global markets by improving the reliability and flexibility as well as reducing costs of freight distribution.

According to Boysen et al. (2013), a container is a cargo-containing box that can be separated from 
Tab. 1. Top trade routes (TEU shipped) in 2013

\begin{tabular}{|c|c|c|c|c|c|}
\hline ROUTE & WEST BOUND & EAST BOUND & NORTH BOUND & SOUTH BOUND & TOTAL \\
\hline Asia - North America & 7739000 & 15386000 & & & 2312500 \\
\hline Asia - North Europe & 9187000 & 4519000 & & & 13706000 \\
\hline Asia-Mediterranean & 4678000 & 2061000 & & & 6739000 \\
\hline Asia - Middle East & 3700000 & 1314000 & & & 5014000 \\
\hline North Europe - North America & 2636000 & 2074000 & & & 4710000 \\
\hline Australia - Far East* & & & 1072016 & 1851263 & 2923279 \\
\hline Asia - East Coast South America & & & 621000 & 1510000 & 2131000 \\
\hline $\begin{array}{l}\text { North Europe/Mediterranean - East Coast } \\
\text { South America }\end{array}$ & & & 795000 & 885000 & 1680000 \\
\hline North America - East Coast South America & & & 656000 & 650000 & 1306000 \\
\hline
\end{tabular}

* Data from 2012

Source: (Drewry Container Forecaster, 2013; World Shipping Council, 2017).

a wagon and to continue transportation by another means, i.e. using a different mode (such as ship or truck). Standardised containers facilitate transportation and higher flows of cargo (Rodrigue, 2013). Among twelve standard containers, Twenty-foot Equivalent Unit (TEU) and Forty-foot Equivalent Unit (FEU) are the two basic standard sizes. 40-foot containers dominate international, especially on long-haul routes, such as from China to Europe.

Container transportation comprises most of the global transportation. According to Drewry Maritime Research, the global container fleet accounted for about 32.9 million TEU in 2012 (World Shipping Council, 2017). Most of this fleet comprises dry containers (standard and special) making up about $89 \%$ of the fleet. Insulated reefer containers and tanks together add up to $7 \%$ of the fleet. Reefers require specific temperature for transportation of goods and amount to approximately $6.25 \%$ of the global fleet. Tank containers used for transport of liquids comprise about $0.75 \%$ of the global fleet. According to the data of Drewry Maritime Research, in 2012, the dry container fleet was approximately 29.3 million TEU, reefer containers -2.1 million TEU, and tank containers - about a quarter million TEU of the total fleet. It is estimated that an average annual growth of containers amounts to 1.6 million TEU.

A trade route refers to a trade between an origin group of countries and a destination group of countries (World Shipping Council, 2017). The top global trade routes described in TEU shipped are presented in Tab. 1.

The substantial differences in TEUs shipped in one direction in comparison to the other direction indicate the scale of the empty container relocation problem.

According to the ranking of the ten biggest container exporters in the World (World Trade Service, 2017), China is the leader of containerised cargo export as in the years 2010, 2013, and 2014 it exported 31.3 - 36 million TEU, respectively). Considering import, China takes the second place after the USA. Therefore, studies of container transportation have to be made through the prism of the trade routes and transport corridors China - USA and China Europe.

Container transportation became a vibrant field for scientific research of the strategic, tactical and operational problems of management. It embraces management of maritime transportation (Lee \& Song, 2017) as well as intermodal transportation (Meers et al., 2017). Most of the studies focus on shipping routing and network analysis (Song \& Dong, 2013), shipping competition, alliances and resource sharing agreements (Xie, 2017) as well as management with environmental issues (Obrecht \& Knez, 2017; Tao et al., 2017). One of the significant research fields is empty container repositioning which is analysed together with routing problems, inventory control, location problems, network planning container leasing prices, etc. (Braekers et al., 2011; Zheng et al., 2017). On the basis of the literature analysis it can be stated that approaching the empty container problem with the assumption that they have their own supply chain which can be modelled in search for optimality is an interesting research problem. 


\section{THE CAUSE OF THE EMPTY-CON- TAINER PROBLEM}

Substantial offshoring of manufacturing activities to Asia and China significantly increased the global container transportation during the latest years (Fransoo at al., 2013). The high imbalance of trade exchange between the countries results in the surplus of empty containers that need to be returned to the owner or moved for further demand. Since China exports much more than imports, its trade imbalance reached almost EUR 200 billion in 2015 (European Commission, 2017). A substantial container surplus is stocked in ports of USA and Europe waiting to be filled and sent further. Notteboom and Rodrigue (2007) indicate that the reason for the empty-container problem is not only trade imbalance but also repositioning costs, container manufacturing, and leasing costs as well as customer preferences for use. All these reasons make empty container repositioning a very complex and topical problem.

The rising demand for container transportation triggers the search for new possibilities and new corridors. Taking trade routes between Asia and Europe as an example, a dynamic growth of infrastructure development can be observed in the route China Europe. It is a part of a Chinese policy embodied in One Belt One Road (OBOR) concept comprising maritime (one Road) and rail or intermodal (One Belt) transportation. In Europe, this concept is most often referred to as the New Silk Road (NSR). There are three main alternative corridors along the NSR (Sahbah, 2014; Nazarko \& Kuzmicz, 2017; Ejdys, 2017) but the Northern Corridor starting with the Russian Trans-Siberian Railway line, then going through Russia, Belarus and Poland. The latter is often referred to by the Chinese as a gate to Europe seems to be most viable. The initiative is financially supported by the Asian Infrastructure Investment Bank and the Silk Road Fund (since 2014). The development of the OBOR concept mostly concentrates on the land part based on railway transport. The advantage of the route is less time needed for transportation in comparison to that using a maritime route, but it is still significantly more expensive than shipping. It is perceived as a middle option between fast and expensive air transportation and cheap but time-consuming shipping.

Rail connections between China and Europe are rapidly developing and they are strongly supported by the central and local authorities of China. The intensity of efforts made by China and countries aspiring to take part in OBOR initiative allows predicting a substantial growth in intermodal transportation which will significantly affect full and empty container supply chains.

\section{THE CONCEPT OF THE EMPTY- CONTAINER SUPPLY CHAIN}

Supply chain management includes decision making about facility location, production, transportation and inventory control (Pirim, Al-Turki \& Yilbas, 2014). Rodrigue et al. (2013) refer to supply chains as commodity chains that functionally integrate a network of production, trade and service activities from the transformation of raw materials through manufacturing stages to delivering of a finished good to the market. It is conceptualised as a series of nodes linked by different transactions including sales and intra-company transfers aiming for added value. Transportation is no longer treated separately from supply chains. Its development significantly influences global supply chains by expanding the territorial range of supply chains. Significant technical development and especially that of intermodal transportation influences the continuity of transportation and supply chains (Rodrigue, 2013).

Containers hold cargo to be shipped and can be treated as a subject of supply chains (Fransoo, 2013; Willis \& Ortiz, 2004). Fig. 1 presents the supply chain concept showing the dual role of containers. It can be assumed that empty containers have their own supply chain which covers containers, container terminals and means of transport, such as trucks, trains or ships (Zain et al., 2014).

Song and Dong (2015) describe container transportation chains (Fig. 2). They consider exporters who require empty containers and shipping companies who provide them to customers. Cargoes are packed into containers at a depot or port and are then transported to another depot or port to wait for vessels. Later, laden containers are transported through sea corridors or by rail corridors to finally arrive at the port or depot of their destination. Subsequently, they are transported to the importers or to a depot to be unpacked. Empty containers can either be stored in an inland depot or moved to a port depot to wait for future use or repositioning to other ports. 


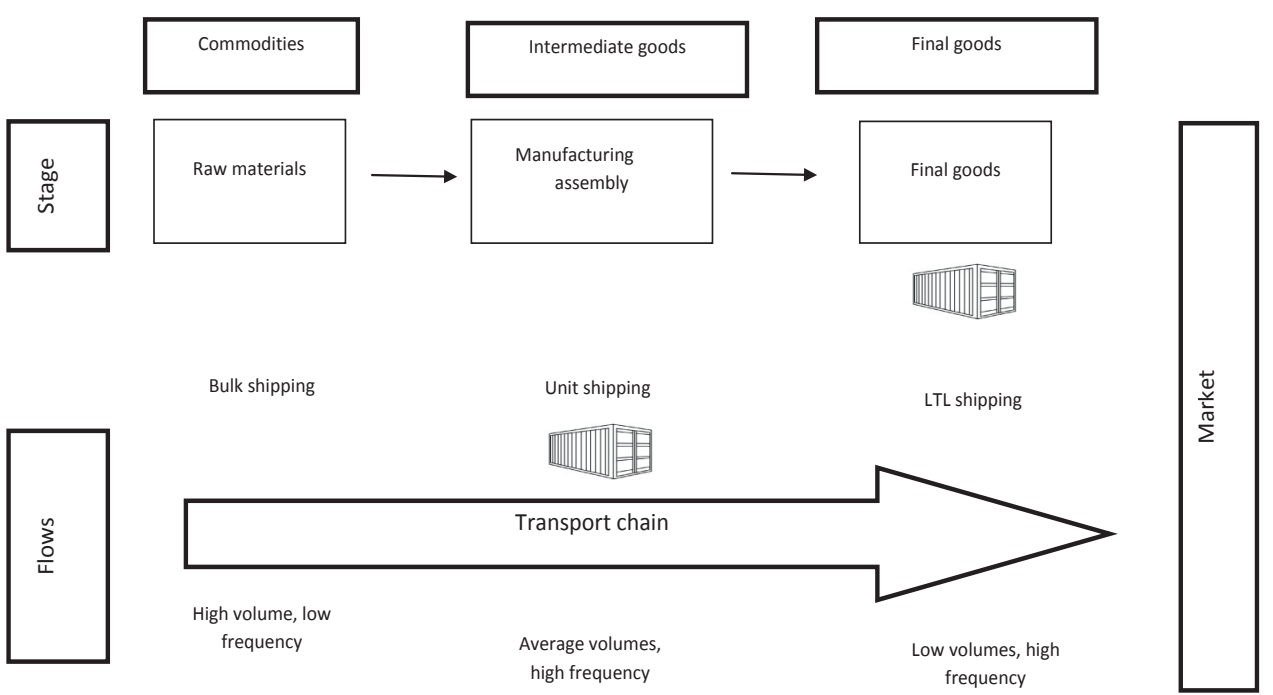

Fig. 1. Containers in the supply chain concept

Source: elaborated by the authors based on (Rodrigue, 2013; Asa, 2017).

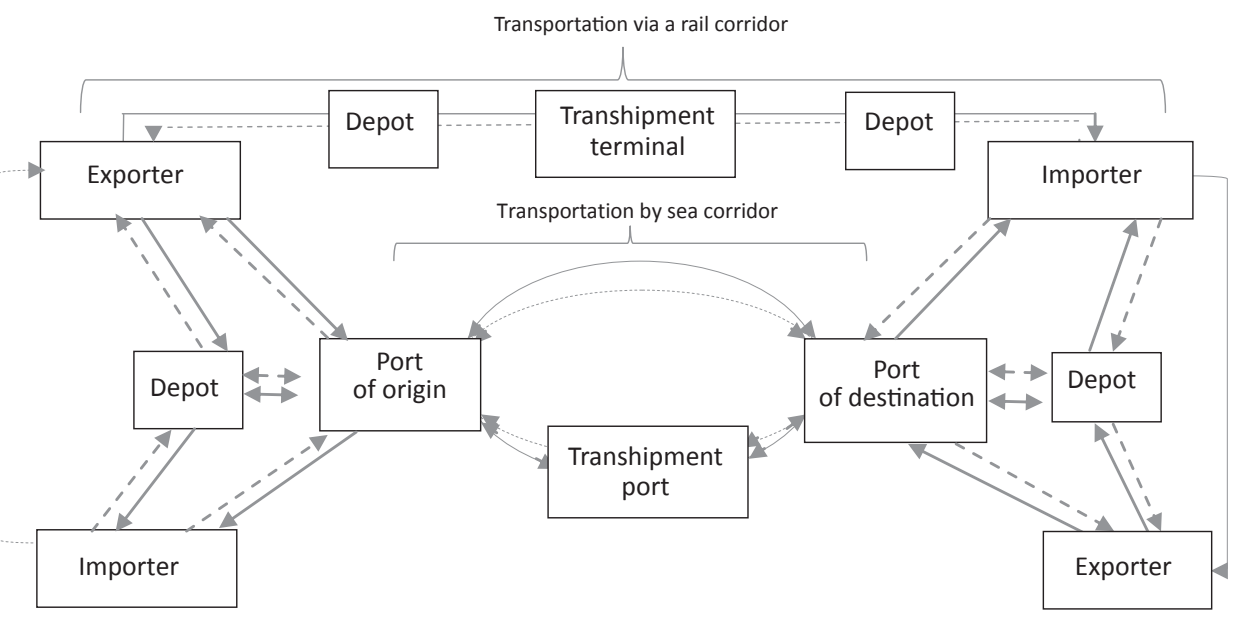

Fig. 2. Container transportation chain

Source: elaborated by the authors based on (Song \& Dong, 2015).

Song and Dong make (2015) underline that this transportation chain actually involves two chains, i.e. the one of laden containers and the other of empty ones. These chains are interconnected and use the same infrastructure. Solid lines in the Fig. 2 designate flows of laden containers and dashed-lines represent flows of empty containers.

\section{PREREQUISITES FOR MODELLING}

Ivanow and Sokolov (2010) indicate three main approaches to supply chain modelling: optimisation, simulation and heuristics. However, a hybrid of these approaches is often applied, joining, for example, simulation and optimisation methods. An extensive survey of these approaches applied in the supply 


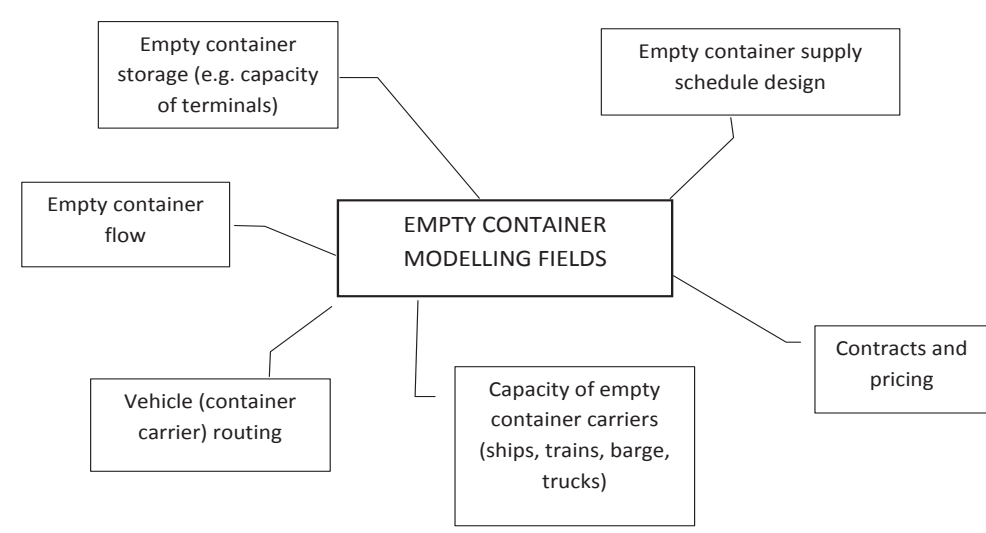

Fig. 3. Empty container modelling fields

Source: elaborated by the authors on the basis of (Breakers et al., 2011; Braekers et al., 2013; Song \& Dong 2015; Mittal et al., 2013; Zheng et al., 2016; Chen et al., 2016).
Supply chains can be modelled as a network design. It can also be referred to as network modelling because it involves the development of a mathematical model of the supply chain (Watson et al., 2014). This model is then solved with optimisation methods. Watson et al. (2014) divide supply chain modelling into modelling to determine the optimal location of facilities (warehouses, plants or suppliers) and the best flow of products through the network structure of this facility.

To formulate a supply chain chain domain is presented in Chandra and Grabis (2007). The difficulty in applying optimisation to supply chains lies in the development of a model that would represent the complexity and uncertainty of the supply chain with satisfying accuracy and would still be relatively simple to solve (Harrison, 2005).

Empty-container repositioning is modelled in the literature as a location problem (Mittal et al., 2013), routing problem (Braekers et al., 2013a), routing and assignment problem (Nossack \& Pesch, 2013), inventory control problems (Dang et al., 2012) or cargo flow optimisation problem (Song \& Dong, 2012). The focus of location problems is the inland depot localisation. Fig. 3 indicates different fields of empty-container modelling. They cover empty container supply schedule design, contracts and pricing, the capacity of empty container carriers such as ships, trains, barge and trucks, vehicle routing as a means of container transportation, empty container flow and storage of empty containers including the capacity of terminals. network model, the following elements are required: an objective function, constraints, decision variables and data. The methodology includes the formulation of the mathematical model and verification of a model by solving a representative set of instances with linear or integer programming methods, or mixed integer programming methods (Fig. 4).

The objective is the goal of the optimisation and the criteria that are used to compare different solutions. It must be quantifiable. In the case of emptycontainer repositioning, the key criterion is cost minimisation. It can minimise costs related to transportation, container rental, delays in delivery of empty containers, etc.

The constraints define the rules for feasible solutions. These are a set of constraints that narrow down the solution space. In empty-containers supply chains, they can restrict the capacity of container depots, define time windows for delivery or restrict the means of empty-container transportation distances in case of transportation or location problems.

In the model of the empty-containers supply chain, the main decision variables can include, for

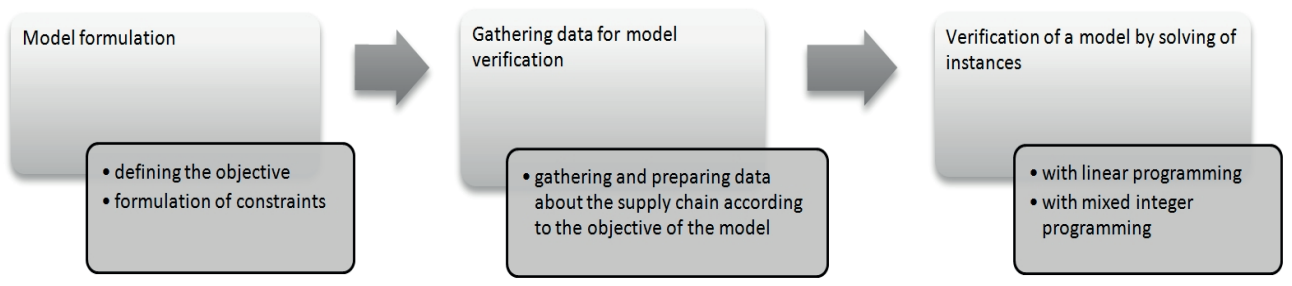

Fig. 4. Methodology of the supply chain modelling with optimisation methods 
instance, the number of containers that should be transported from an importer to an exporter, or from a depot to an exporter; or the number or the location of container depots that should be used. These decision variables must meet the restrictions formulated as constraints.

The model should be then tested using real data, see Kendall et al. (2016). The availability of data is often problematic and, therefore, the model can be tested by running multiple scenarios, considering approximate data, or adjusting the available data (Watson et al., 2014).

Extensive literature is available on the topic of empty-container repositioning. For review, consider Braekers et al. (2011). To illustrate approaches to supply chain modelling, a few examples are given.

A study by Almeder et al. (2009) is an example of applying a mixed integer programming in the context of a discrete-event simulation for a supply chain. The study considers a supply chain network model with different facilities and modes of transport connecting these facilities with a central planner. The objective is to reduce costs by optimising the production/transportation schedule and reducing inventory levels by considering the stochastic environment. They aim at optimal operation plans for supply chain networks using a combination of optimisation with simulation in an iterative form. The study also investigated the influence of contingency time for delays on the quality of the solution.

Sanei et al. (2016) developed a two-stage supply chain network model for a single product system under uncertainty conditions. In the objective function, the total transportation cost of the supply chain network is minimised. Constraints comprise capacities, demand, satisfaction and product flow conservation. Variable cost, fixed charge, supply and demand parameters are in interval forms. Solutions of the instances of the problem are obtained by CPLEX.

A location-inventory problem in modelling supply chains is extensively addressed by Farahani et al. (2015). They provide an in-depth review investigation of the location-inventory models. Four primary types of these models are presented, i.e. is the basic locationinventory problem, dynamic-location-inventory problem, location-inventory-routing problem and inventory-transportation. Most of the mathematical formulations of the models involve binary or integer variables and are simplified by an infinite time horizon, and a continuous review as the predominant inventory policy with a rarely applied periodic review.
They indicate that papers published after 2011 usually reflect real-life conditions in the models such as finite storage and transportation capacity, routing and transportation costs, finite time horizons and secondary objectives including service level and stochastic demand data.

Alharbi et al. (2015) studied schedule design for sustainable container supply chain networks with port time windows. Time windows refer to the time in a week when berths in the ports provide services to the ships. This consideration is an added value of this paper. Schedule decisions are made by liner companies every three to six months. The aim of the study is to minimise the sum of costs (ship costs and fuel costs) ensuring that ports can service the ships on the planned days. Considering port berth services makes this model easily applicable in real-life conditions. In the objective function ship costs, bunker costs and penalty costs are minimised. The sets of constraints include the elimination of asymmetric solutions, ship speed, sailing time, different time components on a round-trip journey, time restrictions on arrivals at ports, and those referring to the availability of berths. The model is a mixed integer nonlinear non-convex model reformulated as an integer linear optimisation model with an iterative approach.

\section{CONCLUSIONS}

The study indicates the expected rise in container transportation resulting from the intense development of transportation corridors within the New Silk Road initiative. In this context, the significance of empty-container relocation connected with great trade imbalance between China and Europe is stressed and denoted as a field of interest for scientific research. An empty-container supply chain is conceptualised, and introductory premises of its modelling are presented. Different fields of modelling in the domain of empty containers are indicated showing how many aspects of this problem need optimisation. Later, some hints for modelling are suggested together with several examples of the modelling application in supply chains.

A further study will include an investigation of empty-container supply chains and a more detailed elaboration of its concept. Applying game theory to find solutions that satisfy different actors of the empty-container supply chain seems to be 
an interesting topic for future research, cf. Kovalyov, \& Pesch (2014). The service provider, i.e. the container transporting company, might be interested in selling their transport places best possible and additionally to satisfy their clients (producers of goods that are supposed to be shipped). As soon as a client's products are ready to be shipped the shipping company is interested to reach the most promising positions in a waiting queue of containers competing for the rare transport positions. The client has an incentive to pay a limited amount for reaching an earlier shipping position in the queue as a compensation to those clients that consequently would suffer from a delayed transport. However as long as the compensation of clients whose transport is postponed covers their additional costs resulting from the delay, they might accept that competitors reach better service positions earlier in the queue. Reaching an earlier service position might lure a client to promise a payment that is higher than the savings gained for the better position. On the other hand, a client whose service is delayed might claim a compensation that is much higher than the shipping company's real cost of the delay. The service provider has an incentive to avoid these resulting instabilities and could try to come up with a mechanism where all clients report the true values. The client receiving a better position would report the true value of her monetary benefit as well as the client moving back in the waiting queue reports the real cost incurred to the service provider. A good mechanism sets incentives to report correct values because lying is risky and would not lead to any competitive advantage for this this mechanism (set of rules). The revenue of the service of the service provider might be independent of the design of the mechanism and is simply a fixed payment, independent of the time interval for shipping. Alternatively the shipping service could be a part of the game. An equilibrium that satisfies all participants of the game so that none of them has an incentive to change their position need not always exit. And even if it exists it might be difficult to find.

In a cooperative game clients might be interested in forming coalitions in order to reduce the shipping costs. Combinatorial auctions would pick the optimal coalitions of jointly bidding clients. A challenging research field could also be dynamic pricing of transportation routes or transportation positions on the vessel or train. Dynamic prices for shipping need not only depend on the attributes linked to the clients and their cargo, as there are the weight, the number of containers, the frequency of shipping, the type of container (foldable if empty, or reefers), the accuracy in delivery (within a specified time interval, etc.) but further heavily depends on the demand within a certain period as well as the demand for specific service (e.g. train, truck, vessel, fast or slow).

Similar questions arise when tucks deliver or pickup containers at the terminal. The service provider and their clients need to agree on time intervals of service to avoid congestions and unnecessary waiting times. Different time intervals may be priced differently in order to equally spread the truck arrivals over the planning horizon.

As storage space at terminals is rare and costly and the number of empty containers that need to be stored might accumulate to a substantial amount, decisions are necessary, where to locate empty container inventory nearby the terminal, in such a way that the delivery costs and access time will be minimal. This additional requires high quality forecasting methods in order to foresee the amount of inbound and outbound empty containers.

One of the major challenges at each sea port is loading and unloading of vessels such the number of reshuffling container moves by berth cranes are small. Reshuffling happens whenever a lower container in a stack is blocked for unloading by containers that need to be removed first to make the lower container in the stack accessible. Reshuffling is a result of poor planning of incoming and outgoing freight between the different ports and also heavily depends on the amount of freight to be unloaded in a port. Closely related is the question of how to stack containers in a vessel and in which order to unload them. If all containers to be unloaded in the next port are stacked on one side of the vessel it is very likely that the vessel will tilt during the loading or unloading procedure. Therefore loading and unloading procedures are required that equally balance the total weight but achieve a fast access to those containers that need to be unloaded next. A high number of empty containers might provide some loading flexibility if the particular container to be accessed is less relevant, but it increases the risk of an unbalanced freight and requires that heavy containers are stored deep down in the vessel.

\section{ACKNOWLEDGEMENTS}

Studies have been carried out within the framework of the grant $\mathrm{MB} / \mathrm{WZ} / 2 / 2016$ and funded by the Polish Ministry of Science and Higher Education. 


\section{LITERATURE}

Alharbi, A., Wang, S., \& Davy, P. (2015). Schedule design for sustainable container supply chain networks with time windows. Advanced Engineering Informatics, 29(3), 322-331.

Almeder, Ch., Preusser, M., \& Hartl, R. F. (2009). Simulation and optimization of supply chains: alternative or complementary approaches? OR Spectrum, 31(1), 95-119.

Asa, Z. (2017). Shipping container. Creative Commons. Retrieved from https://thenounproject.com/term/ shipping-container/116963/

Boysen, N., Fliedner, M., Jaehn, F., \& Pesch, E. (2013). A survey on container processing in railway yards. Transportation Science, 47(3), 312-329.

Braekers, K., Janssens, G. K., \& Caris, A. (2011). Challenges in managing empty container movements at multiple planning levels. Transport Reviews, 31(6), 681-708.

Braekers, K., Janssens G. K., \& Caris, A. (2013a). Integrated planning of loaded and empty container movements. OR Spectrum, 35(2), 457-478.

Braekers, K., Janssens G. K., \& Caris, A. (2013b). Optimal shipping routes and vessel size for intermodal barge transport with empty container repositioning. Computers in Industry, 64(2), 155-164.

Chandra, C., \& Grabis, J. (2007). Supply chain configuration. New York, USA: Springer.

Chen, R., Dong, J. X., \& Lee, Ch-Y. (2016). Pricing and competition in a shipping market with waste shipments and empty container repositioning. Transportation Research Part E: Methodological, 85, 32-55.

Dang, Q-V., Yun, W-Y., \& Kopfer, H. (2012). Positioning empty containers under dependent demand process. Computers and Industrial Engineering, 62(3), 708715.

Ejdys, J. (2017). New Silk Road - A Weak or a Strong Signal? Procedia Engineering, 182, 182-188.

European Commission. (2017). Countries and Regions. China. Trade. Retrieved from http://ec.europa.eu/ trade/policy/countries-and-regions/countries/china

Farahani, R. Z., Bajgan, H. R., \& Kaviani, M. (2015). Location-inventory problem in supply chains: a modelling review. International Journal of Production and Research, 53(12), 3769-3788.

Fransoo, J. C., \& Lee, Ch-Y. (2013). The critical role of ocean container transport in global supply chain performance. Production and Operations Management, 22(2), 253-268.

Harrison, T. P. (2005). Principles for the strategic design of supply chains. In T. P. Harrison, H. L. Lee, J. J. Neale (Eds.), The practice of supply chain management (pp. 3-12). New York, USA: Springer.

Ivanow, D., \& Sokolov, B. (2010). Adaptive supply chain management. London, England: Springer-Verlag.
Kendall, G., Blazewicz, J., Bai, R., de Causemaecker, P., Gendreau, M., John, R., Li, J., McCollum, B., Pesch, E., Qu, R., Sabar, N., Vanden Berghe, G., \& Yee, A. (2016). Good laboratory practice for optimization research. Journal of the Operational Research Society, 67(4), 676-689.

Kovalyov, M. Y., \& Pesch, E. (2014). A game mechanism for single machine sequencing with zero risk. Omega The International Journal of Management Science, 44, 104-110.

Lee, Ch-Y., \& Song, D-P. (2017). Ocean container transport in global supply chains: Overview and research opportunities. Transportation Research Part B: Methodological, 95, 442-472.

Meers, D., Macharis, C., Vermeiren, T., \& van Lier, T. (2017). Modal choice preferences in short-distance hinterland container transport. Research in Transportation Business \& Management, 23, 46-53.

Mittal, N., Boile, M., Baveja, A., \& Theofanis, S. (2013). Determining optimal inland-empty-container depot locations under stochastic demand. Research in Transportation Economics, 42(1), 50-60.

Nazarko, J., \& Kuźmicz, K. A. (2017). Introduction to the STEEPVL analysis of the New Silk Road Initiative. Proceedia Engineering, 182, 497-503.

Nossack, J., \& Pesch, E. (2013). Truck scheduling problem in intermodal container transportation. European Journal of Operational Research, 230(3), 666-680.

Notteboom, T., \& Rodrigue, J. P. (2007). Re-Assessing PortHinterland Relationships in the Context of Global Commodity Chains. In J. Wang, D. Olivier, T. Notteboom, B. Slack (Eds.), Port, Cities and Global Supply Chains (pp. 51-68). London, England: Ashgate.

Notteboom, T., \& Rodrigue J. P. (2008). Containerisation, box logistics and global supply chains: The integration of ports and liner shipping networks. Maritime Economics \& Logistics, 10, 152-174.

Obrecht, M., \& Knez, M. (2017). Carbon and resource savings of different cargo container designs. Journal of Cleaner Production, 155(1), 151-156.

Pirim, H., Al-Turki, U., \& Yilbas, B. S. (2014). Supply Chain Management and Optimization in Manufacturing. Cham, Switzerland: Springer.

Rodrigue, J. P., Comtois, C., \& Slack, B. (2013). The Geography of Transport Systems. London, England, \& New York, USA: Routledge.

Sahbaz, U. (2014). The Modern Silk Road: One Way or Another? Bucharest, Romania: The Black Sea Trust for Regional Cooperation.

Sanei, M., Moahmoodirad, A., \& Niroomand, S. (2016). Two-stage supply chain network design problem with interval data. International Journal of e-Navigation and Maritime Economy, 5, 74-84.

Song, D. P., \& Dong, J. X. (2012). Cargo routing and empty container repositioning in multiple shipping service routes. Transportation Research Part B: Methodological, 46(10), 1556-1575.

Song, D. P., \& Dong, J. X. (2013). Long-haul liner service route design with ship deployment and empty container repositioning. Transportation Research Part B: Methodological, 55, 188-211. 
Song, D. P., \& Dong, J. X. (2015). Empty container repositioning. Handbook of Ocean Container Transport Logistics. Cham, Switzerland: Springer.

Watson, M., Lewis, S., Cacioppi, P., \& Jayaramann, J. (2014). Supply chain network design. Applying optimization and analytics to the global supply chain. New Jersey, USA: Pearson Education.

Willis, H. H., \& Ortiz, D. S. (2004). Evaluating the security of the global containerized supply chain. Santa Monica, USA: RAND Corporation.

World Shipping Council. (2017). Global container fleet. Retrieved from http://www.worldshipping.org/ about-the-industry/containers/global-containerfleet

Tao, X., Wu, Q., \& Zhu, L. (2017). Mitigation potential of $\mathrm{CO} 2$ emissions from modal shift induced by subsidy in hinterland container transport. Energy Policy, 101, 265-273.

Xie, Y., Liang, X., Ma, L., \& Yan, H. (2017). Empty container management and coordination in intermodal transport. European Journal of Operational Research, 257(1), 223-232.

Zain, R. M., Rahman, M. N., Nopiah, Z. M., \& Saibani, N. (2014). Statistics and Operational Research International Conference (SORIC 2013). AIP Conference Proceedings, 1613, 403-419.

Zheng, J., Sun, Z., \& Zhang, F. (2016). Measuring the perceived container leasing prices in liner shipping network design with empty container repositioning. Transportation Research Part E: Logistics and Transportation Review, 94, 123-140. 